\title{
English in Southeast Asia: Pedagogical and policy implications
}

\author{
ANDY KIRKPATRICK*
}

\begin{abstract}
The roles of English within and between the many of the countries which make up Southeast Asia are increasing, and English is constantly being used and negotiated as a mutual means of communication by Asian multilinguals for whom English is an additional language. It is timely, therefore, to consider ways in which these Englishes have been developing, along with the roles English is currently playing. Areas worthy of investigation include the influence of language contact and the motivations for the presence of non-standard forms in these new varieties of English. Given the recent research reviewed in this paper, the criteria by which the use of non-standard forms are classified as characteristic of the particular variety need to be revised. The paper will conclude by considering whether the role of English as a lingua franca in the region has reached its zenith and whether regional language education policy is likely allow the languages of Asia to thrive.
\end{abstract}

\section{INTRODUCTION}

The roles of English within and between the countries which make up Southeast Asia are increasing. In addition to the development of regional varieties of English such as Singaporean and Filipino, for example, which themselves are characterised by innervariation, English has also become the main lingua franca in Southeast Asia. This includes its role as the sole official working language of the Association of Southeast Asian Nations (ASEAN). As a result, English is constantly being used and negotiated as a mutual means of communication by Asian multilinguals for which English is an additional language. This is of particular interest as the English of the region is developing in what could be called post Anglo-cultural contexts. At the same time, several corpora have become available allowing researchers to draw firmer conclusions about the linguistic features of these varieties and uses of English.

It is timely, therefore, to consider ways in which these Englishes have been developing, along with the roles English is currently playing (Bolton 2012). Areas worthy of investigation include the influence of language contact and the motivations for the presence of non-standard forms in these new varieties of English. Given the recent research reviewed in this paper, the criteria by which the use of non-standard forms is classified as characteristic of the particular variety need to be revised. This paper will also explore the extent to which the Englishes of Southeast Asia adopt the pragmatic and cultural norms of its Asian users, and will explore the hypothesis that, when used as a regional lingua franca, speakers will adopt a more 'neutral' register to ensure that people from different linguistic and cultural backgrounds will not be disadvantaged by the use of variety-specific or culturally-specific features or phenomena.

\footnotetext{
*Griffith University, Languages and Linguistics, 170 Kessels Road, Brisbane, Queensland 4111, Australia. E-mail: a.kirkpatrick@griffith.edu.au 
The paper will conclude by considering whether the role of English as a lingua franca in the region has reached its zenith or whether it is likely to take on new roles and in new domains which are divorced from Anglo-cultural influences. The conclusion will also call for empirical research to investigate what is really happening with regard to the teaching of local languages in the school systems to help us investigate whether current regional language education policy and practice is likely to allow the languages of Asia to thrive.

\section{LANGUAGE CONTACT - NON-STANDARD FORMS AND CODE-MIXING}

The motivations for and causes of language change continue to be the subject of great debate (Filppula et al. 2009). The conventional wisdom has been to assume that a speaker's mother tongue necessarily influences the English which that speaker develops. Ansaldo (2010: 498), for example, argues that substrate grammars are highly influential in 'contact language formation', and, as will be illustrated later, gives several compelling illustrations from Singaporean English as evidence for this. While phonological and lexical influences from the L1 can often be readily identified in the L2, it is becoming less clear how the L1 or substrate influences the morpho-syntactic forms of the L2, as the research reviewed below will illustrate.

It is now evident that many new varieties of English share non-standard morpho-syntactic forms and that this therefore questions the essential role of the second language (Deterding \& Kirkpatrick 2006; Mesthrie 2008). In a recent study on the use of the perfect in East and Southeast Asian Englishes, as illustrated in the spoken sections of four corpora of the International Corpus of English, namely Hong Kong, India, Singapore and the Philippines (Seoane \& Suarez-Gomes 2013), the authors' findings indicate that there is a levelling in the use of the present perfect and the simple past in these Asian varieties of English, and that this levelling is also reflected in contemporary British English. It is also a wellknown feature of American English. They conclude that the similarities between the Asian Englishes investigated in their study 'preclude attributing an essential role to influence from the substrate' (Seoane \& Suarez-Gomes 2013: 20).

They also point out that, while the base form of the verb is attested in contexts where the standard would require the present perfect form, it is very rare compared with the use of the standard form (Seoane \& Suarez-Gomes 2013: 11). The question of the presence of a non-standard form and the extent to which mere presence justifies its subsequent classification of being characteristic of the variety is raised by Van Rooy (2013). As he points out, a major advantage of using corpora is that they allow researchers to quantify the use of linguistic features. If, for example, the use of a particular non-standard form occurs only rarely in the output of a speaker and is vastly outnumbered by the use of standard forms, how can this sensibly be classified as a characteristic linguistic feature of that variety? In his study of Black South African English, BSAE, he concludes that many of the features previously described as characteristic of BSAE - including the omission of -ly on adverbs, subject-verb concord - are, in fact, 'occasional performance errors' (Van Rooy 2013: 14).

A similar point is made by Hall et al. (2013) in their study of countability in world Englishes. Using data from the Vienna Oxford Corpus of International English (VOICE) and data drawn from the web, they found that the treatment as countable of nouns which are classified as uncountable in standard British English, was rare, with a maximum usage rate of only 3.5 per cent. Their results also question the essential influence of the L1 upon the 
L2, as their subjects included speakers of languages, some of which mostly use countable grammar (English, Sinhala and Swahli) and those that do not (Filipino, Japanese and Mandarin Chinese). They concluded that while there may be some L1 influence, it is not high. They also concluded that the use 20 ountable use of mass nouns was (a) infrequent, (b) recurrent and (c) widespread, being attestable across numerous L1 backgrounds and geographical regions (Van Rooy 2013: 15).

Further evidence that non-standard linguistic features are shared by many varieties comes from a recent study of the use of the hypothetical subjunctive in South Asian Englishes (Hundt et al. 2012). They state, 'The vast majority of linguistic features in regional varieties of standard(ising) English around the world are shared with other varieties' (Hundt et al. 2012: 147). They also argue that it is difficult to ascribe patterns of variation to a single cause. 'Influence from American English, the different degrees of institutionalisation and, potentially, different grades of exonormative pressure from British English on the individual varieties may be at the root of the gradient we observe' (Hundt et al. 2012: 163).The results of this recent research confirm that caution in assigning a single cause to explain language change is wise because, 'In most cases, no cause can be firmly established and because of the real possibility that multiple causes are responsible for a particular change' (Thomason 2010: 31).

The research cited above all indicates that different varieties share many non-standard morpho-syntactic features, and this suggests that language contact and the influence of the substrate cannot be presented as the major cause. This is not to say that language contact is not a cause of much language change (Mufwene 2009; Schneider 2012) but rather its role in the development of certain non-standard forms needs to be queried. What might be other causes? In noting the presence of a number of non-standard forms across many different varieties of vernacular English, Chambers (2004: 129) has argued for the presence of vernacular universals, that is to say that a collection of non-standard forms exists in all vernacular varieties. Other scholars feel that this claim goes too far. Szmrecsanyi and Kortmann (2009) argue that the morpho-syntactic features found in their survey of 46 varieties of English may be caused for different reasons in different languages.

Is variety type or geography - and thus the influence of the contact languages - the better predictor of distinctive syntactic features? While acknowledging that new varieties of English share non-standard forms, Mesthrie and Bhatt (2008) argue that some varieties prefer to delete certain features while other varieties prefer to retain them. They give Singaporean English with its allowance of subject deletion as an example of a 'deleter' and African languages as good examples of 'retainers' (Mesthrie \& Bhatt 2008: 108). Kortmann (2010), on the other hand, while not dismissing the importance of geography, argues that it is whether the variety is an L1or an indigenised non-native L2 or a creole which better predicts the morpho-syntactic features of the variety.

To conclude this first section of the paper, the existence of corpora is allowing linguists to study the occurrence of non-standard features in new varieties of English with more accuracy than was previously possible. Recent findings suggest that, while still potentially of some influence, the substrate influence may be just one of many causes of linguistic change. The occurrence of so many shared non-standard features remains to be satisfactorily explained. And while the claim that there are a number of vernacular universals appears exaggerated, cognitive phenomema such as the tendencies towards linguistic simplification and regularisation - as evidenced in British English over the centuries by the reduction in the number of verbal inflections and the move towards regular past tense 
forms respectively (Davis 2010a) - may also be playing a role. This move to simplification has been noted in other languages, especially those that have served as lingua francas such as Malay, Chinese and vernacular Arabic (Ostler 2010). McWhorter explains the 'loss of inherited irregularities and complexities' (cited in Ostler 2010: 79) being due to being acquired by a large number of adult learners who failed to fully learn the language so that 'imperfect knowledge of the language became the standard'. This seems unlikely in the case of English, especially given the results of recent research reviewed above, which shows the presence of such non-standard forms, while widespread, is rare. The standard forms remain by far the most commeDt seems possible, if not likely, therefore, that the changes in new varieties of English are caused by similar motivations to changes in traditional Englishes (Davis 2010a).

In this review of the presence and possible explanation of non-standard forms at the morpho-syntactic level, it has been argued that substrate influence may only be just one of several potential causes for the development of these forms. But, it is perhaps easier to assign influence from substrate languages upon other linguistic features, including typology. While typological distance may provide a barrier to contact-induced change, 'under circumstances of intense contact, any linguistic feature can be transferred to any other language' (Thomason 2010: 41). As an example, the close contact of Chinese in the development of Singaporean English appears to have been influential. Singaporean English allows pro-drop constructions in which the subject NP does not need to be explicitly stated, but can be inferred. These examples are headlines taken from the Singaporean Straits Times newspaper (Deterding 2000: 205):

(1) Stole $\$ 58,000$ from shipmaster

(2) Pushed URA officer down

(3) Hurt girlfriend with lighted butt

Standard British English would require a NP in subject position in these sentences. It seems likely that these examples show influence from Chinese as Chinese allows pro-drop sentences, and as Chinese has been spoken in Singapore for generations.

Similarly, topic-comment or topic prominent structures are common in Singaporean English (Ansaldo 2010). Examples from Ansaldo (2010: 507) include:

(4) Expensive the durian here (Durians are expensive here)

(5) That book got already (I already have that book)

Again, Chinese influence seems a likely explanation, as Chinese prefers topic-comment structures (Kirkpatrick \& Xu 2012). Chinese also prefers a clause sequence of subordinate to main which may explain why the Chinese speaker of English below uses a series of 'because' clauses in answer to the question about his feelings for the Great Wall:

(6) Question: When you first got to the great wall, how did you feel?

Response: Some stranger feelings, because I couldn't get the same feeling as others, because others always feel powerful, and happy or others, because I didn't have some special feeling, so I feel sad.

This 'because-therefore' sequence in which several 'because' clauses can precede the 'therefore' or 'so' clause has been identified as a key principle of information sequencing in Chinese (Kirkpatrick \& Xu 2012) and it seems possible that this principle is being 
reflected in the English of this speaker. Singaporean English thus provides an example of a variety which appears to have been influenced by the typology of a contact language.

The causes of language change - whether these be contact-induced or internally motivated - remain areas where research is needed. The development of new corpora, includin the Asian Corpus of English as a lingua franca (ACE), which will be released late in 2010 and which will be the Asian counterpart to the Vienna Oxford International Corpus of English (VOICE), will allow researchers to study these questions in more depth. In the next section, language contact in the form of code-mixing of different types is discussed.

In one sense, all Southeast Asian varieties of English 'are code-mixed varieties', a hypothesis (McLellan 2012: 267) sets out to explore. This is an important point for, as Davis (2010a) has shown, traditional British English is also a code-mixed variety in that it bears the influence of several languages. So, before continuing, it is important to define what is meant by code-mixing and code-switching and to distinguish between a code which combines a matrix language, which supplies the syntactic frame, and an embedded language, which supplies the content words (Myers-Scotton 1993) and one in which two languages appear to be operating equally 'in the construction of a codemixed text' (McLellan 2012: 268). In the first, where a matrix and embedded language combine, substrate influence is obvious, as the English has been 'restructured' by adopting a selection of linguistic features from the other languages the relevant speech community speaks (Mufwene 2001). This can be called code-mixing A (CMA). In the second example of code-mixing, however, there is no obvious substrate influence, as two (or possibly more) languages coexist in complementary fashion. This combined use of more than one language can itself be described as a separate language, requiring full competence in the combined languages to be able to use it successfully. This 'language alternation' type of code-mixing (McLellan 2012: 269) can be called code-mixing B (CMB). A third type of code-mixing is the occasional use of a word from another language, code-mixing C (CMC). This becomes hard to define, or even identify, as languages typically borrow words from other languages and make them their own. So, is someone who announces that 'I am going to call in the feng shui guru' code-mixing by using a word from Chinese (fengshui) and one from Hindi (guru) or simply speaking a variety of English? This would appear to depend on familiarity. An outsider might be expected to understand a Malaysian who talked about a person 'running amok', but not one who talked about Malaysian English being a rojak language.

The question is to what extent are Asian Englishes characterised by these types of code-mixing? Reference to the post-creole continuum of acrolect, mesolect and basilect (Platt et al. 1984) is helpful. Clearly the basilect, the most informal and colloquial of the three 'lects' is likely to contain the most examples of CMA. CMB is most likely when highly educated people of the same speech community interact. As both CMA and $\mathrm{CMB}$ also act as identity markers, a hypothesis would be that they are far more likely to occur in intra-cultural communication where people share the same linguistic and cultural backgrounds, than in intercultural communication where 'outsiders' are involved. In intra-cultural communication, the speakers will use their local variety of English. In intercultural communication, speakers will use English as a lingua franca. This is another research question which the existence of relevant corpora can help provide some answers. In a preliminary study (Kirkpatrick \& McLellan 2012: 667) tentatively confirm these hypotheses and show that the uses of English as a lingua franca 'show a strong orientation to communication rather than expression or negotiation of identities', while the uses of 
Englishes for intra-cultural communication indicate speakers draw on the multilingual repertoires of the relevant speech communities (Kirkpatrick \& McLellan 2012: 666). This is not to say, however, that the use of English as a lingua franca is necessarily bland or culturally denuded, as creativity is also found (Pitzl 2012).

A fourth type of code-mixing can also involve the transfer of pragmatic norms from the speaker's first culture to their use of English and the linguistic realisation of these. Lim (2012) compared the politeness strategies of native speakers of Malay when they spoke Malay and when they spoke English. He found several points worthy of mention. First, he noted that Malay complaints had low levels of directness when the speaker was in a position of power, but high levels of directness when the speaker was more equal with the interactants. He suggested that this might cause problems in intercultural communication as people unfamiliar with politeness practices in Malay might not see the force in complaints made by people in authority. By the same token, people unfamiliar with Malay politeness practices might be offended by the high levels of directness expressed by those not in a position of particular power. ' $[\mathrm{H}]$ igh levels of directness complaints in MalE are influences from Malay predispositions for similar high levels of directness in complaints' (Lim 2012: 347). He concludes that 'The variant of English [...] has been clearly acculturated in Malaysia by Malay politeness strategies' (Lim 2012: 353).

Similar findings have been presented for request patterns in Chinese (Kirkpatrick \& Xu 2002), the linguistic realisation in Persian English of key Persian cultural values (Sharifian 2010) and across many varieties of African Englishes (Wolf 2010). A key difference between this cultural code-mixing and the code-mixing described earlier is that linguistic code-mixing is identifiable. On the other hand, cultural code-mixing is not. Generally speaking, people will judge people using their own cultural norms as criteria (Gumperz 1982). Thus, speakers of British English, unused to such high levels of directness in peer complaints, may judge speakers of Malaysian English to be rude or aggressive in such contexts. It is important, therefore, that further research is undertaken into the transfer of first culture norms and their linguistic realisation into local varieties of English. Given the increasing use of English as a lingua franca across East and Southeast Asia, the study of how the different cultural and pragmatic norms of Asian speakers of English are linguistically realised would be of particular value, along with the communicative strategies such speakers adopt. While some research has suggested that users of English as a lingua franca adopt communicative strategies to help ensure successful communication (e.g. Firth 1996; Kirkpatrick 2007b; Meierkord 2007), there are occasions where these are not so successful (Watterson 2008). High stakes ASEAN meetings conducted in English do not need to be derailed by cross-cultural misunderstandings occasioned by misreading participants' linguistic realisations of their cultural and pragmatic norms. Again, the development of new corpora will allow researchers to investigate these questions more fully.

In this discussion of non-standard forms and code-mixing in Asian varieties of English it has been suggested that substrate influence may be just one cause of the presence of non-standard morpho-syntactic forms. It has also been pointed out, however, that the presence of a non-standard morpho-syntactic form in a variety of English cannot be taken as evidence that it is a characteristic of that variety. Indeed, the use of corpora is showing that the presence of many of these non-standard forms represent occasional aberrations rather than systematic uses. We need therefore to be far more cautious in ascribing nonstandard forms to new varieties of English and to come up with more rigorous criteria than merely attestation for assigning the label 'systematic feature' for non-standard forms. 
Four types of code-mixing were identified and it was argued that CMA was more likely to be found in the basilectal varieties of local Englishes while CMB was more likely to be found in the speech of educated members of the speech community. Both CMA and $\mathrm{CMB}$ are likely to be found in intra-cultural communication and less likely in intercultural communication, where English being used as a lingua franca will be seen. Finally, it was suggested that a fourth type of code-mixing, that involving the linguistic realisation in English of L1 cultural and pragmatic norms may be undetected by people from outside the community and this may give rise to intercultural misunderstanding. In the next section of the paper, the ways in which Asian varieties of English encode local cultures will be further explored, including the ways in which English as a lingua franca, by adapting to and encoding different cultures and cultural systems, is operating outside traditional Anglo-cultural settings.

\section{ENGLISH IN SOUTHEAST ASIA: CULTURAL ENCODING}

Asian varieties of English encode the cultures of their speakers. They do this in a number of ways. They can borrow words from local languages to express culturally specific contexts. Kampong (a Malay village) and adat (traditional customs) are two examples from Malaysian English. They can create innovative neologisms, often involving some form of hybridisation (Kachru 1983: 38) where a local language and English combine to form a culturally specific term. Tiffin carrier and police-wala are two examples. These neologisms may be creatively developed using analogy. Thus British English enthrone leads to enstool and enskin in Ghanaian English as, in Ghana, chiefs, draped in animal skins, are installed on stools (Ahulu 1994). They may translate terms from local languages. Barefoot doctor is an example from Chinese. They can also adopt a word from English but imbue it with new meanings. Thus konfiden carries the negative meaning of overconfident or arrogant in Bruneian English (McLellan 2005: 39).

In addition to this lexical creativity, Asian varieties of English (and, in this, they are no different from other varieties of English) encode their cultures through the transfer of pragmatic and rhetorical norms. An example of the transfer of pragmatic norms was given above in Lim's study of the transfer of politeness practices from Malay into Malaysian English. An example of the transfer of rhetorical norms which I cite frequently (e.g. Kirkpatrick 2007a: 86) is this excerpt from an academic volume on Indian literature in English. This illustrates the importance of extended metaphor in academic Indian English.

Years ago, a slender sapling from a foreign field was grafted by 'pale hands' on the mighty and many-branched Indian banyan tree. It has kept growing vigorously and now, an organic part of its parent tree, it has spread its own probing roots into the brown soil below. Its young leaves rustle energetically in the strong winds that blow from the western horizon, but the sunshine that warms it and the rain that cools it are from Indian skies; and it continues to draw its vital sap from this earth, this realm, this India (Naik \& Narayan 2004: 253).

New varieties of English also encode 'cultural conceptualisations' (Sharifian 2010), key cultural values that define a speaker's culture and therefore need to be expressed in the new variety of English. Sharifian has recently explored this in his study of Australian Aboriginal English and Persian English (Sharifian 2008). This encoding of local cultures within the new variety of English gives the new variety its essence, its life-force, its $q i$. 
The question which arises is whether, when used as a lingua franca, English retains this life force, essential to its survival. In a recent and highly erudite account, Ostler (2010) argues that, not only is English going to be the last lingua franca the world will see, but that it has only a limited time left as the world's lingua franca. In drawing lessons from the development and then demise of earlier lingua francas, such as Latin, Malay and Persian, he shows that lingua francas are spread by conquest, commerce, culture and conversion (religious missions). While all have played a role in the spread of English, he argues that each of these roles is either static or declining. To survive, lingua francas need regeneration for which they need to find a new purpose and/or become accepted as a mother tongue. $\mathrm{He}$ argues that neither of these is evident for English.

In arguing along these lines, Ostler has overlooked the presence of so many different varieties of English which have been acculturated to their speakers' domains and settings. As the Pakistani novelist, Sidhwa (1996: 231, 240), has said, 'English [... ] is no longer the monopoly of the British. We the excolonised have subjugated the language, beaten it on its head and made it ours'. 'We have to stretch the language to adapt it to alien thoughts and values which have no expression in English'.

As part of his argument, Ostler contends that the ownership of English remains resolutely with the native speakers of it, and that only mother tongue speakers can innovate in it.

I infer there is some principle, perhaps a universal principle of human society, that only mother tongue speakers of a language have a natural right (given to them by their language community) to innovate in it. One implication is that it is impossible for those who have consciously learned a new language to establish a new dialect of it (Ostler 2010: 49).

This would appear to ignore the development of world Englishes and the empirically attested theory that varieties of English can become norm providing, freeing themselves from norm-dependency upon exonormative 'standards'. From Kachru's (1983) early seminal work through to Schneider's more recent dynamic model (2007), there is evidence that those who have 'consciously learned a new language' have indeed established new dialects of it.

It is also part of Ostler's argument that, without mother tongue speakers, a lingua franca will die. One problem here lies with the traditional definition of a mother-tongue speaker, which assumes a monolingual society in which all children learn their languages perched upon their mothers' knees. But it is now nothing more than a truism to point out that the monolingual society is, to use a linguistic term, highly marked, while the normal, unmarked society is the multilingual one in which children may learn several languages. Indeed, I have elsewhere argued that the presence of English in the school curricula through East and Southeast Asia, often at the expense of a local language, may result in Asians who are multilingual in several Asian languages being replaced by those who are bilingual in their national language and English (Kirkpatrick 2012). Rather, therefore than seeing English as losing mother tongue speakers, it may be that it is gaining speakers, albeit bilinguals, at a meteoric rate. Ostler's (2010: 285) prediction that more and more nations will embrace 'multilinguality'- he gives South Africa and East Timor as examples - seems hard to accept, given that multilingual nations such as China and Indonesia have embraced a language policy which rigorously promotes a national lingua franca as their respective national language, often at the expense of local languages. Language polices which promote national lingua francas at the expense of local languages while promoting English as the 
major 'foreign' language seem to be more likely to lead to bilingualism in the respective national languages and English rather than to multilingualism in Asian languages. In most cases, the national lingua franca will become the mother tongue (thus Putonghua Mandarin and Bahasa Indonesia will become the mother tongues of increasing numbers of Chinese and Indonesians). In some cases, English may become the mother tongue, as is the case in Singapore, where, in the 2010 census, over 50 per cent of Chinese and Indian Singaporean children aged between 5 and 14 indicated that English was their primary home language (Singapore Department of Statistics 2010).

The second condition Ostler puts forward for the survival of a lingua franca is that it finds a new role. As an example, he gives the ability of Sanskrit to move from being a language of religion, 'a perfect language for the expression of Hindu devotion' to becoming 'the vehicle for a vast secular literature in prose and verse' (Ostler 2010: 178, 179). Varieties of world English have, as indicated above, been able to encode local cultures and there has been an explosion of African and Asian literatures written in English. The excerpt from the book on Indian literature in English quoted above discussed the work of 54 Indian authors writing in English. In short, 'various cultures throughout the world have adopted and re-invented English' (Davis 2010b: 26)

At the same time, it is important to point out that a role as a lingua franca can be realised in many different ways, and sometimes these can be quite limited, as was the case, for example, with pidgin English as a language of trade between British and the Chinese compradores in the nineteenth century treaty-port China (Bolton 2003).Today, however, English acts as a lingua franca across a host of domains. In addition to the traditional lingua franca uses in trade and diplomacy, English is the major lingua franca of higher education; it is the major language of popular culture and literature, albeit creatively mixed with other languages; it remains the major language of the internet. Although Ostler points out that, in the first decade of this century, Arabic was the fastest growing net language, with Chinese second, English remains the major lingua franca of the net. Perhaps most importantly, English is being established as a lingua franca in contexts devoid of AngloAmerican influence. As mentioned above, it is the sole official and working language of the ten Southeast Asian nations which make up the ASEAN group. It is also the working language of the so-called ASEAN +3 group (the 3 comprising China, Japan and Korea) and of the BRIC group (Brazil, Russia, China, India). This shows that English is becoming established in non-Anglo-cultural spheres. This was brought home by Ministers in the Cambodian government who pointed out: You know, when we use English we don't think about the United States or England. We only think about
the need to communicate (cited in Clayton 2006: 233).

We need to know English so that we can defend our interests. You know, ASEAN is not a kissy kissy brotherhood. The countries are fiercely competitive, and a strong knowledge of English will help us protect Cambodian interests (cited in Clayton 2006: 230-231).

English currently encompasses two major and interrelated roles in Southeast Asia. The first role is as local varieties of English which encode local cultures, The second is as a regional and international lingua franca. It is therefore a language of the home, if not a mother tongue as such, and also a language of intercultural communication with increasing penetration into more and more domains, many of which are divorced from any

(C) 2014 John Wiley \& Sons Ltd 
'Anglo-cultural' component. A striking example of this is the increasing use of English in the pesantren, the Islamic boarding schools in Indonesia, a major role of which is to deepen children's knowledge of the Koran. In a 2010 survey, parents of children at pesantren indicated they were in favour of the teaching of English, as long as the materials accorded with Islamic values (Fahrudin 2013). An example of Islamic-influenced ELT is that the use of 'will' to express a future plan or promise is taught using the 'God willing' (insya'Allah) tag to give, 'I will come tomorrow, insya'Allah.' The increasing number of foreign worshippers in the mosques of Jakarta has also led to the use of English as a language for the promotion of Islam, with the traditional seven minute talk after prayers now commonly being delivered in English (Fahrudin 2013).

It would thus appear that its future is secure for the foreseeable future. This is not written with any sense of triumphalism. Rather, as discussed in the concluding section of this paper below, the concern is that the continuing role of English as a lingua franca, along with the promotion of national languages, spells danger for many local and regional languages of Asia.

\section{CONCLUSION}

I conclude this paper by raising topics connected with language education and policy where research is needed. While we know that governments throughout the region have introduced English into the primary curriculum, this has been done in different ways and some governments have recently made significant changes to their language education policy. As an example, the government of the Philippines has recently implemented a new mother-tongue policy whereby twelve languages of the Philippines can be used, where appropriate, as languages of instruction from Primary 1 to Primary 3. This represents a radical change to the Bilingual Education Policy, in place since 1974, through which Filipino and English have been the sole languages of instruction from Primary 1. While this seems a forward-looking policy, empirical research is needed to study how this policy is being implemented, as are longitudinal studies of the type conducted into the use of Lubuguan as a medium of instruction (Walker \& Dekker 2008), to measure the success or otherwise of such programmes.

To take another example, Indonesia is the only country of the ASEAN group that has not made English a compulsory subject in primary school. Indeed, in many government primary schools English is often only taught as a 'local content subject', and for two 35 minute periods a week. These classes are not successful for several reasons, including a lack of suitably qualified teachers and relevant resources. The fact that they are not part of the national examinations gives them low priority and this is a further reason for their lack of success (Hawanti 2013). At the same time the recently introduced 'international standard schools' (sekolah bertaraf internasional) are being criticised for being too elitist, with only the rich being able to afford the fees that the schools charge. The medium of instruction in these schools is supposed to be English for mathematics and science from Primary 4, but there are anecdotal reports of it being introduced much earlier than that in many of these schools. We therefore need empirical research to uncover what is really happening in these different school systems - including the Islamic pesantren schools referred to earlier - with regards language education and languages of instruction. We need to know what languages are actually being taught in primary schools in general. As one critic contends: 
With (the) emerging and mushrooming demand for English, schools then drop the local language in order to give more time to the English teaching. As a result, in the long run, children and the younger generation can no longer speak the local language. This is culturally and linguistically pitiful (Hadisantosa 2010: $31)$.

To take a further example, China has introduced English from Primary 3. It has also promulgated a National Language Law which specifically prescribes Putonghua Mandarin as the sole language of education in the Chinese school system, although exceptions are made for the languages of national minority groups, but with varying degrees of success (Feng \& Adamson 2011). In effect, this means that Chinese languages, such as Cantonese, Hokkien and Shanghainese, cannot be taught in schools, even as subjects. At the same time English is being increasingly used as a medium of instruction in certain schools. There are anecdotal reports, for example, of bilingual Chinese-English schools in urban centres like Shanghai and Nanjing. Again, empirical on the ground research is needed to identify what languages are really being taught and how in these primary schools. This research also needs to discriminate between middle-class urban areas and rural settings in order to test the prediction that the urban-rural divide is being further widened by current language education policies. To try and reduce this divide is a major reason why the Malaysian Government recently abandoned their 7-year old policy of teaching maths and science through the medium of English from Primary 1. English will now be taught only as a subject, with Malay being re-introduced as the language of instruction for maths and science (Gill 2012).

Empirical research of the type outlined in the paper will help answer questions concerning the future of English in the region, both in terms of its linguistic features and its functions. The presence of new corpora will allow researchers to more accurately describe and compare the morpho-syntactic features, code-mixing practices and cultural encodings of the region's Englishes. Studies of language education policies and the extent to which these are actually being implemented in schools will give us a more complete picture of what languages are being learned (and which are not) and to what levels. Can the prediction be supported that Asia will see the decline of the multilingual in Asian languages and the rise of the bilingual who is bilingual in the respective national language and English? Are Asian languages being removed from the school curriculum and does this portend the decline of Asian languages? As Coleman (2010: 17) has argued 'A very effective way of killing a language is to deny it any place in the education system'. Or will the future see the gradual demise of English as a lingua franca, with more and more nations embracing 'multilinguality', as predicted by Ostler (2010)?

I have ended this paper with these open-ended questions in order to indicate that the future directions of English in Southeast Asia remain open to speculation and that they cannot be predicted with certainty.

\section{REFERENCES}

Ahulu, Samuel. 1994. How Ghanaian is Ghanaian English? English Today 10(2). 25-29.

Ansaldo, Umberto. 2010. Contact and Asian varieties of English. In Ray Hickey (ed.), The Routledge handbook of language contact, 498-517. London: Routledge.

Bolton, Kingsley. 2003. Chinese Englishes: A sociolinguistic history. Cambridge: Cambridge University Press.

Bolton, Kingsley. 2012. World Englishes and Asian Englishes: A survey of the field. In Andy Kirkpatrick \& Roland Sussex (eds.), English as an international language in Asia, 13-26. Dordrecht: Springer. 
Chambers, J. K. 2004. Dynamic typology and vernacular universals. In Bernd Kortman (ed.), Dialectology meets typology: Dialect grammar from a cross-linguistic perspective, 124-145. Berlin: Mouton de Gruyter.

Clayton, Thomas. 2006. Language choice in a nation under transition: English language spread in Cambodia. Boston: Springer.

Coleman, Hywel. 2010. Teaching and learning in Pakistan: The role of language in education. Islamabad: The British Council.

Davis, Daniel. 2010a. Standardized English: The history of the earlier circles. In Andy Kirkpatrick (ed.), The Routledge handbook of world Englishes, 17-36. London: Routledge.

Davis, Daniel. 2010b. The inclusivity of world Englishes. World Englishes 29(1). 21-26.

Deterding, David. 2000. Potential influences of Chinese on the written English of Singapore. In Adam Brown (ed.), English in Southeast Asia, 201-209. Singapore: National Institute of Education.

Deterding, David \& Andy Kirkpatrick. 2006. Emerging Asian Englishes and intelligibility. World Englishes 25(3/4). 391-410.

Fahrudin, Dididng. 2013. English language teaching material development in pesantren institutions: A transcultural flow experience in Indonesia. Paper presented at the 5th COTEFL Conference, 11-12 May, Purwokerto, Indonesia.

Feng, Anwei \& Bob Adamson. 2011. Trilingual education in minority regions of China. Comparative Education Bulletin 13(1). 47-52.

Filppula, Markku, Juhani Klemola \& Heli Paulasto. 2009. Vernacular universals and language contacts: An overview. In Markku Filppula, Juhani Klemola \& Heli Paulasto (eds.), Vernacular universals and language contacts: Evidence from varieties of English and beyond, 1-16. London: Routledge.

Firth, Alan. 1996. The discursive accomplishment of normality: On 'lingua franca' English and conversation analysis. Journal of Pragmatics 26. 237-259.

Gill, Saran Kaur. 2012. The complexities of re-reversal of language-in-education policy in Malaysia. In Andy Kirkpatrick \& Roland Sussex (eds.), English as an international language in Asia, 45-62. Dordrecht: Springer.

Gumperz, John J. 1982. Discourse strategies. Cambridge: Cambridge University Press.

Hadisantosa, Nilawati. 2010. Insights from Indonesia. In Richard Johnstone (ed.), Learning through English: Policies, challenges and prospects, 24-46. London: British Council.

Hall, Christopher J., Daniel Schmidtke \& Jamie Vickers. 2013. Countability in world Englishes. World Englishes 32(1). $1-22$.

Hawanti, Santhy. 2013. When teachers of English speak up their knowledge and beliefs about ELT in primary schools. Paper presented at the 5th COTEFL Conference, 11-12 May, Purwokerto, Indonesia.

Hundt, Marianne, Sebastian Hoffman \& Joybrato Mukherjee. 2012. The hypothetical subjunctive in South Asian Englishes. English World-wide 33(2). 147-164.

Kachru, Braj B. 1983. The Indianization of English. New Delhi: Oxford University Press.

Kirkpatrick, Andy. 2007a. World Englishes: Implications for English language teaching and intercultural communication. Cambridge: Cambridge University Press.

Kirkpatrick, Andy. 2007b. The communicative strategies of ASEAN speakers of English as a lingua franca. In David Prescott (ed.), English in Southeast Asia: literacies, literatures and varieties, 121-139. Newcastle: Cambridge Scholars Publishing.

Kirkpatrick, Andy. 2012. English in ASEAN: Implications for regional multilingualism. Journal of Multilingual and Multicultural Development 33(4). 331-344.

Kirkpatrick, Andy \& James McLellan. 2012. World Englishes and/or English as a lingua franca. In Jan ul Gee \& Michael Handford (eds.), The Routledge handbook of discourse analysis, 654-669. London: Routledg (

Kirkpatrick Andy \& Xu Zhichang. 2002. Chinese pragmatic norms and 'China English' World Englishes 21(2). 269-280. Kirkpatrick, Andy \& Xu Zhichang. 2012. Chinese rhetoric and writing. Anderson, SC: Parlor Press.

Kortmann, Bernd. 2010. Variation across Englishes: Syntax. In Andy Kirkpatrick (ed.), The Routledge handbook of world Englishes, 400-424. London: Routledge.

Lim Beng Soon. 2012. Transfers of politeness strategies: Some preliminary findings. In Ee-Ling Low \& Azirah Hashim (eds.), English in Southeast Asia: Features, policy and language in use, 343-354. Amsterdam: John Benjamins.

McLellan, James. 2005. Malay-English language alternation in 2 Brunei Darussalam online Internet chatrooms. PhD, Curtin University.

McLellan, James. 2012. The view from below: Code-switching and the influence of substrate languages in the development of Southeast Asian Englishes. In Ee-Ling Low \& Azirah Hashim (eds.), English in Southeast Asia: Features, policy and language in use, 267-288. Amsterdam: John Benjamins.

Meierkord, Christiane. 2007. Multilingual settings with English as lingua franca. In Helga Kotthoff \& Helen SpencerOatey (eds.), Handbook of intercultural communication, 199-218. Berlin: de Gruyter.

Mesthrie, Rajend. 2008. Synopsis: Morphological and syntactic variation in African and in South and Southeast Asia. In Rajend Mesthrie (ed.), Varieties of English. Africa, South and Southeast Asia, 624-635. Berlin: Mouton de Gruyter.

Mesthrie, Rajend \& Rakesh Bhatt. 2008. World Englishes. Cambridge: Cambridge University Press.

Mufwene, Salikoko. 2001. The ecology of language evolution. Cambridge: Cambridge University Press. 
Mufwene, Salikoko. 2009. Some offspring of colonial English are Creole. In Markku Filppula, Juhani Klemola \& Heli Paulasto (eds.), Vernacular universals and language contacts: Evidence from varieties of English and beyond, 280-303. London: Routledge.

Myers-Scotton, Carole. 1993. Duelling languages: Grammatical structure in code-switching. Oxford: Clarendon Press.

Naik, M. K. \& Shyamala A. Narayan. 2004. Indian English literature 1980-2000: A critical survey. New Delhi: Pencraft International.

Ostler, Nicholas. 2010. The last lingua franca. London: Penguin.

Pitzl, Marie-Luise. 2012. Creativity meets convention: Idiom variation and remetaphorization in ELF. Journal of English as a Lingua Franca 1(1). 27-56.

Platt, John, Heidi Weber \& Ho Mian Lian. 1984. The new Englishes. London: Routledge \& Kegan Paul.

Schneider, Edgar W. 2007. Postcolonial English: Varieties around the world. Cambridge: Cambridge University Press.

Schneider, Edgar W. 2012. Contact-induced change in English worldwide. In Terttu Nevalainen \& Elizabeth Closs Traugott (eds.), The Oxford handbook of the history of English, 572-581. Oxford: Oxford University Press.

Seoane, Elena \& Cristina Suarez-Gomez. 2013. The expression of the perfect in East and Southeast Asian Englishes. English World-wide 34(1). 1-25.

Sharifian, Farzad. 2008. Cultural schemas in L1 and L2 compliment responses. A study of Persian-speaking learners of English. Journal of Politeness Research 4(1). 55-80.

Sharifian, Farzad. 2010. Semantics and pragmatic conceptualisations within an emerging variety: Persian English. In Andy Kirkpatrick (ed.), The Routledge handbook of world Englishes, 442-456. London: Routledge.

Sidhwa, Bapsi. 1996. Creative processes in Pakistani English fiction. In Robert J. Baumgardner (ed.), South Asian English: Structure, use and users, 231-240. Urbana, IL: University of Illinois Press.

Singapore Department of Statistics. 2010. Press release: Census of population 2010. http://www.singstat.gov.sg. (14 May, 2013.)

Szmrecsanyi, Benedikt \& Kortmann, Bernd. 2009. Vernacular universals and angloversals in a typological perspective. In Markku Filppula, Juhani Klemola \& Heli Paulasto (eds.), Vernacular universals and language contacts: Evidence from varieties of English and beyond, 33-53. London: Routledge.

Thomason, Sarah. 2010. Contact explanations in linguistics. In Raymond Hickey (ed.), The Routledge handbook of language contact, 31-47. London: Routledge.

Van Rooy, Bertus. 2013. Corpus linguistic work on Black South African English. English Today 29(1). 10-15.

Walker, Stephen L. \& Diane E. Dekker. 2008. The Lubuagan mother tongue education experiment (FLC). A report of comparative test results. Manila: Summer Institute of Linguistics International.

Watterson, Matthew. 2008. Repair of non-understanding in international communication. World Englishes 27(3/4). 378406.

Wolf, Hans-Georg. 2010. East and West African Englishes: Differences and similarities. In Andy Kirkpatrick (ed.), The Routledge handbook of world Englishes, 181-196. London: Routledge.

(Received 13 June 2014)

(c) 2014 John Wiley \& Sons Ltd 


\section{MARKED PROOF}

\section{Please correct and return this set}

Please use the proof correction marks shown below for all alterations and corrections. If you wish to return your proof by fax you should ensure that all amendments are written clearly in dark ink and are made well within the page margins.

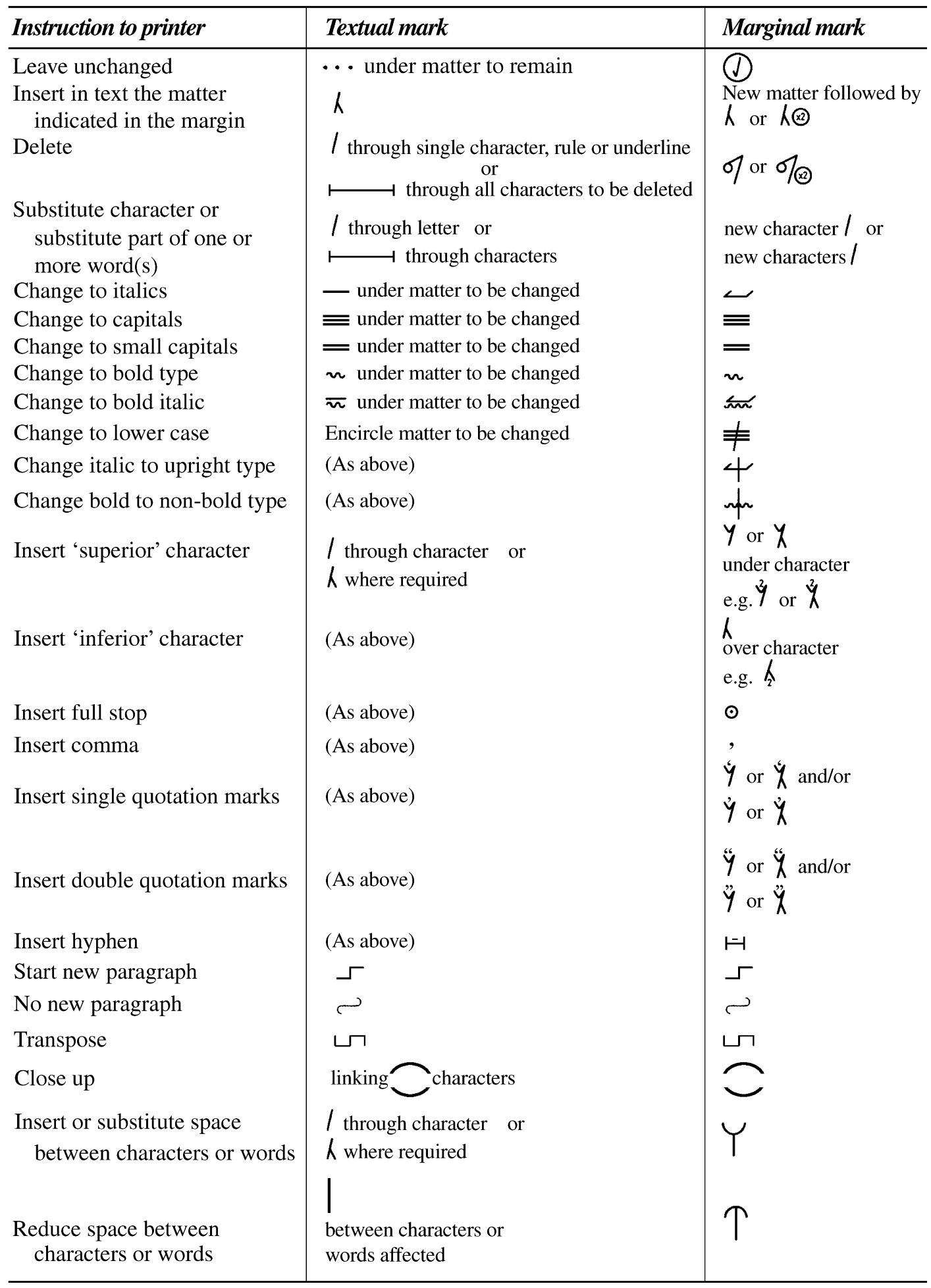




\section{USING ACROBAT EDITING TOOLS}

When you open your PDF file you should see the Comment \& Markup toolbar* listing, from the left, the Sticky Note, Text Edits, Stamp and Highlighter tools, like this:

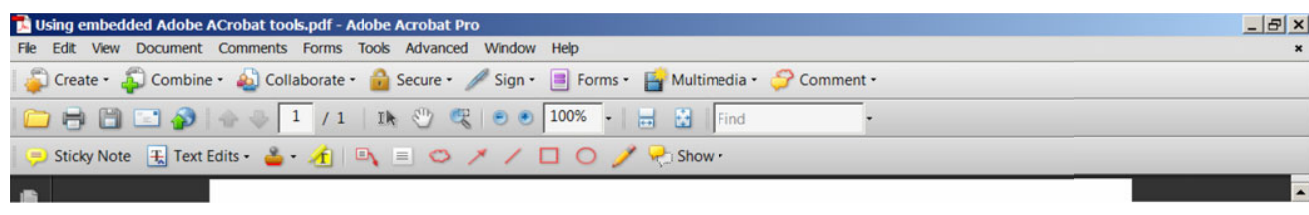

Sticky note

Use this to make comments and give instructions. Click on the tool (think of this as putting paint onto a paint brush), then click on the place in the document where you want make a comment. Type in your instruction into the yellow bubble that appears.

Text edits (use these to make corrections in the text)

To insert text: click on the text edit tool, insert the cursor at the point where you want insert text and start typing.

To replace text: click on the text edit tool and select the text you want to replace (the selection will be highlighted in blue). Start typing the replacement text (you do not need to delete anything).

To delete text: text: click on the text edit and select the text you want to delete and press 'delete' on the keyboard.

Stamp: there is no need to use this tool.

Highlighter

Use this to make a specific instruction (e.g. to change a phrase to italics). Click on the yellow pencil then select the text to be highlighted. Right click on the tool to open the highlighter box and type in you text, e.g. '<remove italics>'.

These are the only tools you need to use to mark up your document. It is best to give an instruction only once to make your corrections easy to read and understand (don't duplicate the sticky note and the text editing tool, for example).

Changing your edits: click on the edited text and change as required.

Deleting your edits: right click on the blue caret or blue or red crossed-out line, bubble or highlighted text and press 'delete' on the keyboard.

Reviewing your edits: click open 'Show comments list' in the Comments toolbar. Every correction you have made will be listed in the bottom pane that opens (to close, it click the right hand arrow at the top of the Comments pane).

*If you do not see the Comment \& Markup toolbar, click on Tools, click on Comment \& Markup then at the bottom of the menu, click on 'Show Comment \& Markup toolbar'.

\section{EXAMPLES}

\begin{tabular}{lll}
\hline Sticky note & A bubble that you can click on to open & \\
\hline Insertion & A blue caret at the point of insertion & it really is time we asked where we are going. \\
\hline Replacement & $\begin{array}{l}\text { A blue caret and blue line crossing out } \\
\text { the text }\end{array}$ & it really is time we asked where we are going. \\
\hline Deletion & A red line crossing out the text & it really is time we asked where we are going. \\
\hline $\begin{array}{l}\text { Highlighted } \\
\text { text }\end{array}$ & Text is highlighted in yellow & is time we asked where we are going. \\
\hline
\end{tabular}

